\title{
Photoredox-Enabled Deoxygenative Cross-Coupling of Alcohols Activated by NHCs
}

\section{Key words}

nickel catalysis

iridium catalysis

deoxygenative cross-coupling

$$
\begin{aligned}
& \mathrm{X}-\text { (Het)Ar }+ \text { HO-Alk } \\
& \begin{array}{l}
\text { (1.0 equiv) } \\
\mathrm{X}=\mathrm{Cl}, \mathrm{Br}
\end{array}
\end{aligned}
$$

$\mathrm{NHC}$ (1.6 equiv) pyridine, $t$-BuOMe, r.t., 5 min

then $1.5 \mathrm{~mol} \% \operatorname{Ir}(\mathrm{ppy})_{2}(\mathrm{dtbbpy}) \mathrm{PF}_{6}$ $5 \mathrm{~mol} \% \mathrm{NiBr}_{2} \cdot \mathrm{dtbbpy}$, quinuclidine $t$-BuOMe-DMA (1:1), blue LEDs, $2 \mathrm{~h}$

$$
\begin{aligned}
& \vdots \\
& \vdots \\
& \vdots \\
& \vdots \\
& \vdots \\
& \vdots
\end{aligned}
$$
$>150$ examples Selected examples:

Proposed mechanism:

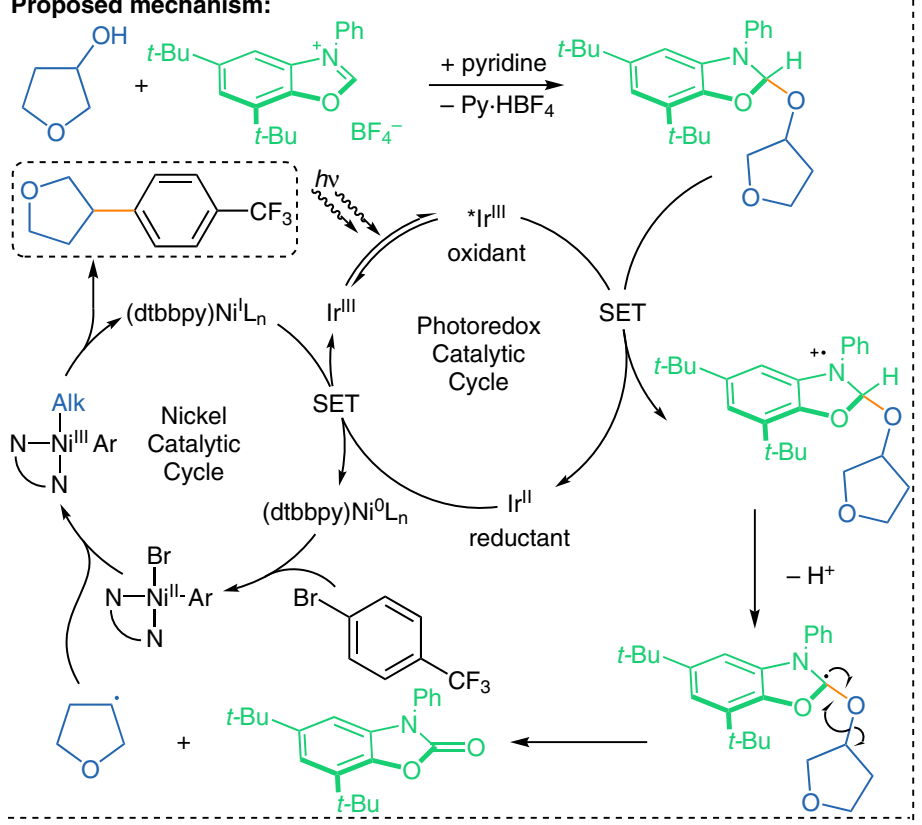

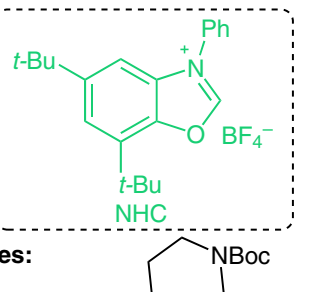

photochemistry

\section{Synfact in of the Month}

Significance: The authors report a nickel-catalyzed photo-enabled deoxygenative cross-coupling between $\mathrm{C}\left(\mathrm{sp}^{3}\right)$-hybridized alcohols activated through an $\mathrm{N}$-heterocyclic carbene salt with aryl halides. The procedure enables coupling of highly functionalized primary, secondary and tertiary alcohols.
Comment: Late-stage functionalizations of complex molecules such as a taxol variants and multiply protected saccharides are shown. A reaction mechanism is proposed in which the NHC salt plays a key role in providing the thermodynamic driving force for the reaction. 